\title{
Incorporación de la institución de la caución al artículo 320 del Código Procesal Civil para el resarcimiento de daños y perjuicios
}

\author{
Incorporation of the institution of the surety to article 320 of the Civil Procedure \\ Code for the compensation of damages and losses
} Incorporação da instituição da fiança ao artigo 320 do Código de Processo Civil para
a indenização de perdas e danos

Artículo recibido en julio 2019

Arbitrado en agosto 2019

Publicado en octubre 2019

\section{Mildred Maguiña Acebey \\ maguiña.m@yahoo.es \\ ORCID: 0000-0002-9934-3542}

RESUMEN

ABSTRACT

RESUMO
El estudio, está focalizado en el estudio del resarcimiento de lo ocasionado a raíz de la solicitud de medidas cautelares, 'por lo tanto, el objetivo de la investigación fue la incorporación de la institución de la caución al artículo 320 del Código Procesal Civil para el resarcimiento de daños y perjuicios. Fue elaborada con una metodología de tipo descriptiva, con un diseño documental de campo, un enfoque cuantitativo- cualitativo y los métodos usados fueron, histórico, lógico, y análisis, síntesis. Las técnicas para la recolección de dato fueron cuestionario y entrevistas, los instrumentos estuvieron conformados por encuestas y una guía, aplicado a 100 abogado de diversas ciudades, 4 especialistas, 2 vocales, 4 jueces y 4 instrucción en materia civil. Se obtuvo como resultado la elaboración de una propuesta, que garantizara el cumplimiento de las medidas cautelar, para evitar estar frente a una inseguridad jurídica, que debilita los estamentos de Bolivia.

Palabras clave: Caución; código procesal civil; derecho procesal civil, medidas cautelares

The study is focused on the study of compensation for what was caused as a result of the request for precautionary measures, 'therefore, the objective of the investigation was the incorporation of the institution of the surety to article 320 of the Civil Procedure Code for the compensation for damages. It was developed with a descriptive methodology, with a field documentary design, a quantitative-qualitative approach and the methods used were historical, logical, and analysis, synthesis. The techniques for data collection were questionnaires and interviews, the instruments were made up of surveys and a guide, applied to 100 lawyers from different cities, 4 specialists, 2 members, 4 judges and 4 instruction in civil matters. As a result, a proposal was drawn up to guarantee compliance with the precautionary measures, to avoid facing legal uncertainty, which weakens the Bolivian estates.

Key words: Surety; civil procedure code; Civil procedural law, precautionary measures

O estudo está centrado no estudo da indenização pelo que foi ocasionado em decorrência do pedido de medidas cautelares, 'portanto, o objetivo da investigação foi a incorporação da instituição da fiança ao artigo 320 do Código de Processo Civil para a compensação por danos. Foi desenvolvido com metodologia descritiva, com delineamento documental de campo, abordagem quantitativo-qualitativa e os métodos utilizados foram histórico, lógico e análise, síntese. As técnicas de coleta de dados foram questionários e entrevistas, os instrumentos constituídos por enquetes e um roteiro, aplicados a 100 advogados de diferentes cidades, 4 especialistas, 2 membros, 4 juízes e 4 instrutores em matéria civil. O resultado foi a elaboração de uma proposta que garantisse o cumprimento das medidas cautelares, a fim de evitar a insegurança jurídica que fragiliza as propriedades bolivianas.

Palavras chave: Fiança; código de processo civil; Direito processual civil, medidas cautelares 


\section{INTRODUCCIÓN}

La Caución es concebida como mecanismo reparador de los daños y perjuicios que a consecuencia de la ejecución de una medida cautelar pudiera ocasionarse a quien deba soportarla. De allí, que a pesar de encontrarse del lado de la tutela cautelar que en principio beneficia solamente a su titular, resulta innegable que termina beneficiando a quien soporta tal medida y ello en atención a su fin reparador.

Para Croskey (2009), la caución es "la garantía exigida al peticionario de la medida cautelar para asegurar el pago de las costas y los daños y perjuicios que pudieran resultar si la medida fue solicitada sin derecho o con abuso del derecho". ( $p$ 45).

Por su parte Castellanos (2014), señala que:

El otorgamiento por su beneficiario, de una caución que asegure a la otra parte el resarcimiento de los daños que aquellas puedan ocasionar, se funda en la hipótesis de haber sido pedidas indebidamente. La contra cautela por consiguiente, asegura al destinatario de la medida la efectividad del resarcimiento de los posibles daños y concreta, en cierto modo, la igualdad de las partes en el proceso.(p. 80).

De esta forma, es pertinente señalar, que no siempre el beneficiario de lacaución es el demandado, por cuanto podría darse que se afecte por error el bien de un tercero; de ahí que la norma indique que la caución tiene por objeto asegurar al afectado con una medida cautelar el resarcimiento de los daños y perjuicios que pudiese causarle su ejecución.

Es importante tener en cuenta que la caución, se acrecienta cuando la pretensión principal, anticipada con la medida cautelar, es rechazada, entonces se sostienen que la caución basada en el principio de igualdad, se constituye en el contrapeso de la expedición de la medida cautelar.

En este sentido Croskey (2009) considera la medida cautelar como:
"Aquellas que el juez dispone para impedir que el presunto deudor realice actos de disposición $\mathrm{o}$ de administración que disminuyan su responsabilidad patrimonial y convierta en ilusorio el resultado del juicio. Las medidas cautelares tienen el objeto de asegurar la eficacia, el resultado práctico de la resolución que se vaya a dictar en el juicio.". (pág.19).

La importancia de la caución se acrecienta cuando la pretensión principal, anticipada con la medida cautelar, es rechazada, entonces se sostienen que la 
caución basada en el principio de igualdad, se constituye en el contrapeso de la expedición de la medida cautelar.

Los anteriores criterios destacan la relevancia que tiene el instituto de la caución en materia cautelar, siendo este instituto un elemento esencial para garantizar los daños emergidos de una medida sin derecho.

Es la posición del Nuevo Código Procesal Civil boliviano, donde se suprime el instituto de la caución como presupuesto de aplicabilidad para la procedencia de las medidas cautelares situación que da lugar a la interrogante ¿Cómo garantizar el resarcimiento de daños y perjuicios del demandado cautelado, en el Estado Plurinacional de Bolivia?, teniendo como objeto de estudio las medidas cautelares del Nuevo Código Procesal Civil, , se ha planteado como el campo de acción de la investigación, el resarcimiento de los daños y perjuicios del demandado cautelado.

En este sentido, la investigación tiene como objetivo principal la incorporación de la institución de la caución al artículo 320 del Código Procesal Civil para el resarcimiento de daños y perjuicios del estado plurinacional de Bolivia. La investigación se justifica porque integra una novedad científica y aportes teóricos; el primero, porque radica en la elaboración de una propuesta de incorporación del instituto de la caución al Nuevo Código Procesal Civil, cuyo diseño se identificó núcleos temáticos investigativos, que se introduce a la actividad científica investigativa, con la finalidad de garantizar el resarcimiento de daños y perjuicios del demandado cautelado en el Nuevo Código Procesal Civil. Y el segundo, ya que, está orientada a ofrecer un modelo jurídico cuyo objetivo es, garantizar el resarcimiento de daños y perjuicios del demandado cautelado en el Nuevo Código Procesal Civil.

\section{Marco histórico}

\section{El derecho procesal civil}

A través de la historia, se observa que los primeros en actuar en una seudo democracia fue Grecia, ya que tenía una organización jurisdiccional con dos características: la especialidad (dividiendo los conflictos en civiles y penales) y la colegialidad de sus órganos (cada persona que colaboraba en la resolución de conflictos tenía una especialidad y el órgano jurídico se hallaba formado por un grupo plural de personas).

Ya en la Edad Media, después de la Revolución francesa se adoptó algunos postulados como la separación de poderes, justicia gratuita, inamovilidad de los jueces, igualdad ante la ley, obligaciones de fundamentar las sentencias, todo esto plasmado en su Código de Procedimiento Civil francés de 1804. 
La Edad Contemporánea a su vez, aportó con el origen, consolidación y nacimiento de nuevas instituciones procesales, se incluyeron los términos de pretensión jurídica y diferencia entre acción y derecho.

Sin embargo, los fundamentos más importantes se aprecian desde el siglo XIX con las doctrinas del Derecho francés, Derecho germano (Wilndscheid, Bulow, Kolher) y en el Derecho italiano (Chiovenda, Carnelutti, Calandrei, Betti, Lipari).

\title{
Clasificación de los procesos según el código de procedimiento civil.
}

La clasificación según el Código de Procedimiento Civil boliviano:

Procesos de conocimiento. En los artículos, 316- 485 CPC que comprende los procesos ordinario, sumario y sumarísimo.

Procesos de ejecución. En los artículos, 486-561 CPC y artículo, 48 al 61 de la Ley N¹760, comprende: los procesos ejecutivos, de ejecución coactiva de garantías reales, ejecución de sentencias y ejecución de sentencias dictadas en el extranjero.

Procesos especiales. En los artículos, 562- 786 CPC, 52-59 de la Ley 1760 que comprende: I) los procesos concursales (concurso necesario y concurso voluntario) II)los procesos interdictos (interdicto de adquirir la posesión, retener la posesión, de retener la posesión de recobrar la posesión, de obra nueva perjudicial o daño temido); III) los procesos de desalojo (desalojo de vivienda y desalojo de locales y comercio, industria y otros); IV) los procesos voluntarios (declaratoria de herederos, renuncia de herencia y aceptación con beneficio de inventario; comprobación, apertura y protocolización de testamentos, inventarios, división de herencia y de otros bienes comunes, mensura, deslinde, rendición de cuentas, declaratoria de ausencia y presunción de muerte, bienes vacantes y mostrencos, oferta de pago y consignación), V) los procesos arbitrales; VI) procesos de conciliación.

Esta diversidad de procesos tiene por finalidad normar los procedimientos que rigen la normativa procesal civil.

\section{Clasificación de los procesos según el nuevo código procesal civil}

El nuevo Código Procesal Civil, tiene la siguiente clasificación de procesos:

\author{
I.- Proceso Ordinario \\ II.- Procesos Extraordinarios III.- Procesos Monitorios \\ IV.- Procesos Concursales V.- Procesos voluntario
}

Después de realizar la clasificación que existe en el Código de Procedimiento Civil actual y en el Nuevo Código Procesal Civil, es pertinente mencionar que el proceso en sí, tiene una doble función, que es de dar lugar a la efectividad de los derechos 
reconocidos en la Ley sustantiva y el acceso a los valores de paz, orden y seguridad, que son de interés de toda la colectividad, por tal motivo, se observa varios tipos de procesos, los cuales son aplicados según el caso.

\section{Medidas cautelar}

La terminología usada para estas medidas especiales, las cuales son usadas en la tramitación de los procesos, varía según los tipos de sistemas de procesos de cada país, ya que en algunas legislaciones son conocidas como medidas de seguridad, medidas de garantía, acciones preventivas, aseguramiento de bienes litigiosos y medidas precautorias, este último utilizado en la legislación boliviana.

Las medidas cautelares, tiene su posible origen en el derecho romano, donde ya presentaban las acciones preventivas. Ulpiano ya describía un instituto conocido con el nombre de Edictum Carbonianum, el cual tenía como fin proteger los derechos hereditarios del menor de edad, suspendiendo el proceso hasta el tiempo de la pubertad, concediendo al impúber la misio in bona que consistía en la concesión de bienes con carácter provisorio, pero siempre que aparecieran verosímiles, este es un excelente ejemplo para un antecedente remoto de las actuales medidas cautelares. El romanista, Emilio Betti conocido por sus grandes aportes a la teoría del acto jurídico, hace referencia a las "estipulaciones pretorias", que tenían como finalidad: prevenir con toda probabilidad un juicio posible al asegurar prácticamente a través de su efecto jurídico, la directa satisfacción del interés digno de tutela. Tejero, $(2014$, p.1)

Las medidas cautelares surgen desde el derecho romano donde existieron instituciones cautelares que ya se practicaban debido a la importancia que estas tenían dentro de un proceso, de hecho no se las tenía de manera sistematizada, sino más bien, de forma dispersa.

\section{Medidas cautelares en el Código de Procedimiento Civil}

En el Código de Procedimiento Civil artículo 156, está establecido las clases de medidas precautorias, las cuales son:

Anotación preventiva. -"Asiento temporal y provisional de un título en el Registro de la Propiedad, como garantía precautoria de un derecho o de una cosa futura". Ossorio, (2002, p. 87) Debe entenderse que la anotación preventiva de demanda es una "medida cautelar que aprovecha la publicidad registral para advertir a terceros de la existencia de un litigio". (Barona, 2006, p. 151).

Embargo preventivo. "Medida procesal precautoria de carácter patrimonial que, a instancia del acreedor o actor, puede decretar un juez o tribunal sobre los bienes del 
deudor o demandado, para asegurar el cumplimiento de la obligación exigida y las resultas generales del juicio". Ossorio (2002, p. 381).

Secuestro. Medida cautelar que "consiste en la aprehensión judicial y depósito de la cosa litigiosa o de bienes del deudor presunto, a fin de asegurar la eficacia del embargo y el eventual resultado del juicio". Couture, (2004, p.663).

Intervención judicial. Medida cautelar que consiste en la "designación por el juez, en los casos autorizados por la ley, de una persona a quien se asigna el cometido de vigilar un patrimonio, con el objeto de proteger el derecho eventual que en él pueda tener un litigante". Couture, (2004, pág.425)

\section{Medidas cautelares en el nuevo Código Procesal Civil}

Medidas cautelares genéricas. El artículo 324 del Código Procesal Civil dispone, fuera de los casos previstos en los artículos que siguen, quien tuviere fundado motivo para temer que durante el tiempo anterior al reconocimiento judicial de su derecho, éste pudiere sufrir un perjuicio inminente o irreparable, podrá solicitar las medidas urgentes que según las circunstancias, fueren las más aptas para asegurar provisionalmente el cumplimiento de la sentencia.

\section{Medidas cautelares específicas}

Del art. 325 al 337 del Nuevo Código Procesal Civil, se establece las clases de medidas cautelares, como:

- Anotación Preventiva

- Embargo Preventivo y Secuestro

- Intervención Judicial

- Inhibición de Bienes

- Prohibiciones de Innovar y Contratar

Así mismo, es necesario, hacer referencia del artículo 320 del Nuevo Código Procesal Civil, donde si bien, todas estas medidas cautelares mencionadas anteriormente están plasmadas en este Nuevo Código, este artículo señala la procedencia de tales medidas sin necesidad de dar caución, con excepción de una sola, que es la intervención judicial, artículo citado a continuación.

Artículo. 320 (medidas sin contra cautela). Las medidas cautelares podrán ordenarse bajo responsabilidad de la parte solicitante, sin necesidad de dar caución. La autoridad judicial deberá fundar su decisión en consideración a la verosimilitud del derecho, el peligro en la demora, la posibilidad jurídica y la proporcionalidad de 
la medida. Sin embargo, se requerirá contra cautela cuando se trate de intervención judicial y en los casos señalados por ley.

Como se aprecia, ya no es necesario ofrecer caución excepto en la intervención judicial y otras señaladas por ley; vale decir, que ninguna de las medidas citadas anteriormente no necesitara caución, situación que deja al demandado sin la oportunidad de que se le garantice el resarcimiento del daño que podría sufrir, si en caso se le haya demandado sin derecho, por otro lado cuando el artículo menciona en los casos señalados por ley, lo hace de manera muy general y subjetiva.

\section{MÉTODO}

La metodología de la investigación fue de tipo descriptivo, ya que, se realizó un registro detallado del comportamiento específico de dos variables identificadas. Siendo, los daños y perjuicios del demandado cautelado, la variable dependiente y la institución de la caución la variable independiente.

Seguidamente, el diseño de la investigación fue del tipo documental y de campo, porque se realizó la recolección de datos a partir de la revisión bibliográfica, recopilación documental especializada, al igual que la recolección de datos a partir de la realidad observada, por tanto en un determinado momento, y la investigación de campo, dado a que se utilizaron; los cuestionarios y entrevistas para poder conocer, lo que piensan los Administradores de Justicia y el mundo litigante.

Así mismo, la investigación estuvo desarrollada bajo un enfoque mixto (cuantitativo y cualitativo). Se toma el enfoque cuantitativo porque se pretende obtener la recolección de datos para conocer o medir el fenómeno en estudio y encontrar soluciones para la misma; la cual trae consigo la afirmación o negación de la situación problemática teniendo en cuenta además, que en la etapa del diagnóstico se realizó la tabulación y recolección de información de datos estadísticos. Y se asumió el enfoque cualitativo, porque se pretende conocer lo que piensa el mundo litigante del resarcimiento de los daños y perjuicios del demandado.

Los métodos que se usaron para el desarrollo de la investigación fueron: histórico - lógico, con la finalidad de estudiar el problema en su desarrollo histórico desde los orígenes, su influencia e importancia en el derecho boliviano hasta nuestros días.

Análisis - síntesis, con la finalidad de sistematizar la información sobre el tema y de los diferentes criterios sobre la caución, y su importancia en la legislación comparada. También se realizará el análisis de la recolección de datos de campo, para luego realizar la síntesis correspondiente, mismos que serán utilizados en el marco teórico y el diagnóstico. Inductivo - Deductivo, con la finalidad de estudiar los elementos particulares para lograr la elaboración de conclusiones y viceversa, durante el proceso de estructuración de la propuesta de la incorporación de la 
caución para garantizar los daños y perjuicios del demandado cautelado en el Nuevo Código Procesal Civil.

Por otro lado, las técnicas utilizadas para la recolección de datos fueron;

Estudio documental. Porque se acopió información sobre la situación del demandado, las garantías en cuanto al resarcimiento de daños y perjuicios en un proceso de precautorio y su importancia de la misma.

Encuesta a abogados. Ya que, se permitió realizar el diagnóstico sobre la problemática de la investigación.

Entrevista a jueces y vocales. Para conocer sus criterios sobre la importancia de que el demandado cautelado tenga el resarcimiento de daños y perjuicios en el proceso, en caso de darse una demanda sin derecho y su importancia.

Entrevista a expertos. Permitió conocer la importancia que tiene en un proceso precautorio, tener la garantía del resarcimiento de los daños y perjuicios de las partes y caso contrario que consecuencias jurídicas puede conllevar esta situación.

Los instrumentos que se aplicaron para la recolección de datos

Cuestionario. Se utilizó para obtener datos estadísticos y tener una información fidedigna de la situación del problema. En ese sentido se realizó una guía de preguntas acerca da la problemática del resarcimiento de los daños y perjuicios del demandado cautelado, lo cual nos servirá para la recopilación de datos de información de tipo escrito con el fin de recabar hechos y opiniones de los abogados litigantes de la ciudad de Potosí, Sucre y La Paz en Bolivia.

Entrevista personal. Fue dirigida a especialistas en materia civil, a vocales de sala civil y a jueces de partido e instrucción en materia civil, quienes proporcionaran la información y orientación fidedigna sobre la situación actual del problema planteado, para el sustento legal de la propuesta.

A su vez, la población, se entiende como la totalidad de fenómenos a estudiar en donde las unidades poseen una característica común, la cual se estudia y da origen a los datos de la investigación. Y la muestra, es una parte o porción de una población. La investigación optó por un muestreo no probabilístico e intencional, teniendo como muestra a 100 abogados en ejercicio por ciudad, Potosí, Sucre y La Paz, a 4 especialistas a nivel nacional del área civil a los 2 vocales de sala civil del distrito de Potosí, a los 4 jueces de Partido y 4 de Instrucción en materia civil del distrito de Potosí.

\section{RESULTADOS}

Para medir el estado actual del resarcimiento de los daños y perjuicios del demandado cautelado, se estableció dos dimensiones: "Las medidas cautelares" y "La caución". En base a las dimensiones mencionadas, los indicadores establecidos y la 
aplicación de entrevistas y encuestas a personas del área, con el método de encuesta se logró obtener información importante, en este sentido, el orden del análisis es el siguiente:

- Entrevista aplicada a expertos, vocales y Jueces civil.

- Encuesta aplicada a los abogados del distrito de Potosí. De esta forma se desarrolla el análisis tanto cuantitativo como cualitativo con referente al logro del objetivo propuesto por la presente investigación.

\section{Criterio sobre la relación en el instituto de la caución}

En la entrevista que se le realizó al informante 1, ex asistente perteneciente al Tribunal Constitucional de Bolivia, expresó que el instituto de la caución tiene sus raíces en derecho romano, usada como cautela o caución que servía de garantía, lo cual ha servido de base para una de las mayorías de las legislaciones de carácter civil, en este sentido la caución es considerada como una garantía.

También, se realizó la entrevista al informante 2, ex magistrado del Tribunal Constitucional de Bolivia y Ex Vocal de la Sala Civil de la Corte Superior de Distrito de Potosí, el cual, indicó que la caución es una institución que sirve para responder, de los posibles daños y perjuicios que puedan ocasionarse al demandado, si con posteridad la sentencia se declara improbada.

Por lo tanto, los criterios con relación al instituto de caución, es que permite el derecho de la persona contra quien se va interponer una medida precautoria, y la caución vista como la garantía que le queda al demandante, para asegurar el pago de daños y perjuicios.

\section{Importancia y el beneficio de la caución}

En este caso, un informante, ex Asistente del Tribunal Constitucional de Bolivia, comentó que la importancia de la caución, está en otorgar una garantía a la parte que se le ha impuesto una medida precautoria para que resarza los daños y perjuicios, el beneficio radica en que la parte a quien se le ha impuesto la medida tiene la oportunidad de ejecutar los daños que se le ha ocasionado

Otro informante, ex magistrado del Tribunal Constitucional de Bolivia y ex Vocal de la Sala Civil de la Corte Superior de Distrito de Potosí, indicó que la caución es importante porque actúa como un mecanismo, para afrontar la responsabilidad exigida al demandante de la medida precautoria. Según la doctrina se puede mencionar varios beneficios que trae esta institución, sin embargo, solo menciona uno, que es evitar que se incurra en desigualdad legal de las partes provocando una clara indefensión. 
Por consiguiente, la importancia de la caución radica en su naturaleza, y sirve de garantía para el resarcimiento de daños y perjuicios. También es una garantía que beneficia al demandado

\section{La caución como garantía de resarcimiento en los daños y perjuicios de la parte solicitante}

En esta oportunidad, todos los informantes indicaron que sí consideran que la caución garantiza el resarcimiento de daños y perjuicios de la parte del solicitando , dado a que está en su finalidad y es netamente necesario.

\section{Criterio sobre la supresión de la caución en el Nuevo Código Procesal Civil}

El personal entrevistado indicó que, están en total desacuerdo con la supresión de la contra cautela o caución, ya que, puede originar la vulneración de varios principios.

\section{Riesgo que traen consigo la supresión de b caución, en el Nuevo Código Procesal Civil, para el desarrollo del proceso, y la protección del derecho}

Los entrevistados, señalaron que efectivamente se corre un riesgo por la supresión de la caución en el Nuevo Código Procesal Civil, debido a que la caución, aunque esté basada en principios procesales, están ligados a los principios fundamentales, además va traer consecuencias al incurrir en una desigualdad procesal y con esto se afecta el debido proceso.

Dado a los resultados obtenido, por los expertos y los vocales se puede decir, que ambos concuerdan con los puntos de vista a cerca de la importancia, los beneficiosy las consecuencias de la supresión de la caución en el Nuevo Código de Procedimiento Civil, de esta manera, se puedo evidenciar con la entrevista que el 100 $\%$ de la muestra está de acuerdo con la existencia del problema planteado.

Ahora bien, el mismo instrumento fue utilizado para la entrevista de jueces de partido y de Instrucción en materia civil del distrito judicial del departamento de Potosí. Por lo tanto, pudo determinar que la mayoría de los entrevistados concuerdan en la importancia y beneficios que tiene la caución para la procedencia de las medidas precautorias, al mismo tiempo mostraron su desacuerdo en cuanto a la supresión de la caución en el Nuevo Código Procesal Civil en un 100\%.

Por otro lado, para el desarrollo de la investigación se llevó acabo la aplicación del Cuestionario en los Abogados de la ciudad de Potosí, Sucre y La Paz en Bolivia. 


\section{Medidas precautorias garantizan que se cumpla las sentencias}

La tabla 1, muestra que el total de la población de profesionales entrevistados confirmó que sí, están de acuerdo en sostener que las medidas precautorias garantizan el cumplimiento de la sentencia.

Tabla1. Garantía de las sentencias

\begin{tabular}{ccc}
\hline ALTERNATIVAS & FRECUENCIA & $\%$ \\
\hline $\mathrm{Si}$ & 100 & 100 \\
$\mathrm{No}$ & 0 & 0 \\
\hline TOTAL & $\mathbf{1 0 0}$ & $\mathbf{1 0 0}$ \\
\hline
\end{tabular}

De esta forma, se evidenció que dentro del proceso precautorio, la procedencia de las medidas precautorias es de suma importancia para garantizar la sentencia, la cual la convierte en eficaz

\section{Las medidas precautorias en la tramitación de los procesos}

Según los datos obtenidos, se muestra en la tabla 2, que en la tramitación de procesos, las medidas precautorias el $75 \%$, indicó que el uso constante de la misma, añadiendo a este porcentaje la segunda opción que es el de casi siempre, a la vez mostrando un uso frecuente de las medidas precautorias.

Tabla 2. Frecuencia de las solicitudes

\begin{tabular}{ccc}
\hline ALTERNATIVAS & FRECUENCIA & $\%$ \\
\hline Siempre & 75 & 75 \\
Casi siempre & 20 & 20 \\
Nunca & 5 & 5 \\
\hline TOTAL & $\mathbf{1 0 0}$ & $\mathbf{1 0 0}$ \\
\hline
\end{tabular}

En este sentido los resultados, destacaron que las medidas precautorias son realmente importantes y necesarias dentro de los procesos civiles, ya que estas, aseguran la ejecución de la sentencia de manera eficaz. Siendo que las medias precautorias son tramitadas constantemente, por su parte la caución también tiene la misma frecuencia de aplicación, en el desarrollo de los procesos. 


\section{La caución visto como requisito para la procedencia de medidas precautorias}

En la tabla 3, se detalla que la totalidad de los abogados encuestados, sostienen que la caución es un presupuesto de aplicabilidad de las medidas precautorias.

Tabla 3. Requisitos

\begin{tabular}{ccc}
\hline ALTERNATIVAS & FRECUENCIA & $\%$ \\
\hline $\mathrm{Si}$ & 100 & 100 \\
$\mathrm{No}$ & 0 & 0 \\
\hline TOTAL & $\mathbf{1 0 0}$ & $\mathbf{1 0 0}$ \\
\hline
\end{tabular}

Según, la encuesta realizada se puede constatar que, para que procedan las medidas precautorias, necesariamente debe ofrecerse caución por parte del demandante, siendo éste un requisito que establece el Código de Procedimiento Civil actual.

\section{En el presente la coacción garantiza el principio de igualdad entre las partes}

Seguidamente en la tabla 4, destaca que el $80 \%$ de los abogados, que se han sometido a la encuesta, sostienen que la caución garantiza el principio de igualdad entre las partes, con un resultado de un $20 \%$ de abogados tienen una opinión diferente.

Tabla 4. La coacción como garantía de los principios de igualdad en la actualidad.

\begin{tabular}{ccc}
\hline ALTERNATIVAS & FRECUENCIA & $\%$ \\
\hline $\mathrm{Si}$ & 80 & 80 \\
$\mathrm{No}$ & 20 & 20 \\
\hline TOTAL & $\mathbf{1 0 0}$ & $\mathbf{1 0 0}$ \\
\hline
\end{tabular}

La caución no solo actúa como una garantía para el resarcimiento de daños, sino también como un instituto que garantiza la igualdad de las partes, porque con la procedencia de la caución las partes se encuentran en igualdad, con las mismas oportunidades, con los mismos derechos y obligaciones. 


\section{Efectos generados por la eliminación de la caución en el Nuevo Código Procesal Civil}

La tabla 5, muestra que, el $80 \%$ de los abogados, piensan que con la supresión de la caución se va a vulnerar la igualdad de las partes, mientras que el $20 \%$ tiene una posición diferente.

Tabla 5. Efectos por la eliminación de la coacción en el Nuevo Código Procesal Civil.

\begin{tabular}{ccc}
\hline ALTERNATIVAS & FRECUENCIA & $\%$ \\
\hline $\mathrm{Si}$ & 80 & 80 \\
$\mathrm{No}$ & 20 & 20 \\
\hline TOTAL & $\mathbf{1 0 0}$ & $\mathbf{1 0 0}$ \\
\hline
\end{tabular}

Se señaló que con la supresión de la caución, se va a vulnerar el principio de la igualdad, que es un principio que rige todos los procesos, siendo este un principio ligado a principios constitucionales, el momento que se suprime la caución este principio es vulnerado, ya que el demandado va estar en desventaja frente al demandante, en este sentido lo que busca la caución es un equilibrio procesal entre las partes.

Por consiguiente, la información que se obtuvo al aplicar los instrumentos de recolección expuso, que sin la presencia de la caución como presupuesto de aplicabilidad para las medidas cautelares, se estará frente a un problema real, donde se introduce un desequilibrio en el sistema jurídico, dando lugar a la vulneración de derechos fundamentales del demandado de una medida cautelar. Tales resultados demandaron la propuesta que se señala a continuación.

Para finalizar el estudio propuso la incorporación al artículo 320 de la ley 439 del código procesal civil la institución de la caución como presupuesto de la aplicabilidad de las medidas cautelares"; apoyada en la teoría sistematizada y en los resultados obtenidos.

Propuesta sobre la incorporación al artículo 320 del nuevo código procesal civil la institución de la caución como presupuesto de aplicabilidad de las medidas cautelares

\section{Fundamentación jurídica}

\section{Constitución Política del Estado}

El artículo 180. Indica que la jurisdicción ordinaria se fundamenta en los principios procesales de gratuidad, publicidad, transparencia, celeridad, probidad, honestidad, legalidad, eficacia, accesibilidad, e igualdad de las partes ante el juez 


\section{Ley de Órgano Judicial}

El artículo 3013. Establece que la igualdad de las partes ante el juez. propicia que las partes en un proceso, gocen del ejercicio de sus derechos y garantías procesales, sin discriminación o privilegio de una con relación a la otra.

\section{Código de Procesamiento Civil}

El artículo 3. Sobre los Deberes de los Jueces y Tribunales plantea que los deberes de los jueces y tribunales, radica en tomar las medidas necesarias para asegurar la igualdad efectiva de las partes en todas las actuaciones del proceso.

\section{Código Procesal civil}

El artículo 1. Se señalan los principios del proceso civil se sustenta, entre ellos se tiene, la Igualdad procesal, donde la autoridad judicial durante la sustanciación del proceso tiene el deber de asegurar que las partes, estén en igualdad de condiciones en el ejercicio de sus derechos y garantías procesales, sin discriminación o privilegio entre las partes.

La propuesta surgió a consecuencia de la supresión de la caución para la procedencia de medidas cautelares que se halla establecido en el art. 320 del Código Procesal Civil, supresión que fue realizada sin tener fundamentos jurídicos que sustenten esta posición, siendo que el argumento central es para beneficiar al litigante de escasos recursos, lo cual no tiene un asidero legal, toda vez que en el Código de Procedimiento Civil del año 1976 en el artículo 173 dispone que la medida precautoria, solo se decretara bajo responsabilidad de la parte solicitante quien deberá dar caución por las costas y daños y perjuicios que pudiere ocasionar en caso de haber pedido sin derecho y en el parágrafo II del mismo artículo se establece que, la garantía no se exigirá cuando fuere el Estado, Municipalidades o cuando fuere un beneficiario de gratuidad, lo cual demuestra que para garantizar los derechos de las personas de escasos recursos se tiene el beneficio de gratuidad que en el Nuevo Código Procesal Civil es la exención de costas y costos que se halla establecida su tramitación en el art. 222 al 226 del Nuevo Código Procesal Civil, en base a lo señalado se observa que no hay una sustentación coherente, porque ya existe la tramitación del beneficio de gratuidad y en el Nuevo Código Procesal Civil como se mencionó está la tramitación de exención de costas y costos, de regreso al tema, existe una contraposición donde el demandado con la medida cautelar, está siendo privado del derecho a la igualdad de las partes que se tiene en la tramitación de los procesos, es por ese motivo, que es necesario la modificación del art. 320 del Código Procesal Civil con referencia a la procedencia de la medidas cautelares con la prestación de caución. 
Por cuanto, la Asamblea Legislativa Plurinacional, ha sancionado la siguiente Ley:

\title{
LA ASAMBLEA LEGISLATIVA PLURINACIONAL
}

\section{E C R E T A:}

ARTíCULO ÚNICO. La presente ley tiene por objeto modificar el artículo 320 de la Ley N439 de 19 de Noviembre de 2013 Código Procesal Civil, con el siguiente texto.

\begin{abstract}
"Artículo 320 (MEDIDAS CON CONTRACUATELA). Las medidas cautelares podrán ordenarse bajo responsabilidad de la parte solicitante quien deberá dar caución por las costas y daños y perjuicios que pudiera ocasionar en caso de haberla pedido sin derecho. Esta garantía no se exigirá cuando el solicitante fuere el Estado, las municipalidades, o un beneficiario de exención de costos y costas. La autoridad judicial deberá fundar su resolución en consideración a la verosimilitud del derecho, el peligro en la demora la posibilidad jurídica y la proporcionalidad de la medida".0988722300
\end{abstract}

Es dada en la Sala de Sesiones de la Asamblea Legislativa Plurinacional, a los dieciocho días del mes de abril de dos mil quince años.

Fdo. Eugenio Rojas Apaza, Marcelo William Elío Chávez, Efraín Condori López, Roxana Camargo Fernández, Carlos Aparicio Vedia, Ángel David Cortés Villegas.

Por tanto, la promulgo para que se tenga y cumpla como Ley del EstadoPlurinacional de Bolivia.

Palacio de Gobierno de la ciudad de La Paz, a los veintinueve días del mes de diciembre del año dos mil catorce.

FDO. EVO MORALES AYMA, Juan Ramón Quintana Taborga, ElizabethSandra Gutiérrez Salazar, Claudia Stacy Peña Claros, Amanda Dávila Torres.

CONCLUSIONES

Tomando en cuenta los resultados obtenidos al aplicar los instrumentos de la investigación, se puede decir que se logró cumplir con el objetivo principal, al destacarse la necesidad sobre la caución dentro de la solicitud de medidas 
cautelares, porque es la única manera de garantizar un proceso eficaz, donde ninguna de las partes quede en indefensión o en desventaja frente al otro. En tal sentido, hay un desacuerdo en cuanto la supresión de la caución como presupuesto de aplicabilidad de las medidas cautelares.

Un Estado constitucional tiene que ofrecer mecanismos necesarios para que las personas se hallen garantizadas en los daños y perjuicios que se les pueda ocasionar, por tal motivo con la propuesta se garantiza el cumplimiento de las medidas cautelar, y así se evita estar frente a una inseguridad jurídica, que debilita los estamentos del País.

\section{REFERENCIAS}

Barona, S. (2006).Medidas cautelares en el arbitraje, Navarra

Castellanos, G. (2004). Código de Procedimiento Civil. Cochabamba - Bolivia: Ed. Alexander

Código de Procedimiento Civil de Bolivia, Decreto Ley N. 12760 vigente desde el 2 de Abril de1976, Elevado al rango de Ley, por Ley 1760, de fecha 28 de febrero de 1997. La Paz-Bolivia: Ed. Jurídica Témis

Croskey, S. (2009). Medidas Cautelares y Debido Proceso. Asunción - Paraguay: Primera Ed
Ossorio, M. (2002). Diccionario de Ciencias Jurídicas, Políticas y Sociales. Argentina: Ed. Heliasta

Constitución Política del Estado, ley n³942

Couture, E. (2004). Vocabulario Jurídico. Argentina: Tercera Ed.

Tejero, M. (2014). ¿Es adecuada la ausencia de contradictorio previo para la concesión de tutela cautelar en el ordenamiento peruano? Lima - Perú 